\title{
Students' Perspective On The Impact Of The Title III Program On Doctoral And Professional Programs At Minority Serving Institutions: An Analysis Using A Multilevel Rasch Rating Scale Model
}

\author{
Aloyce R. Kaliba, Southern University and A\&M College, USA \\ Kimberly K. Powell, Southern University and A\&M College, USA \\ Walter L. Crockett, Jackson State University, USA
}

\begin{abstract}
We assessed the impact of Part B, section 326 of the Title III program using data from three historically Black Universities. The Title III program aims at strengthening the resource capacity of Historically Black Colleges and Universities (HBCUs) with eligible doctoral and professional programs. The lack of documented quantitative impact contributes to skepticism regarding program efficacy. A web-based survey instrument was used to collect data from students across five domains: research and instruction; technology development; facilities improvement; student financial assistance; and student services. A multilevel Rasch Rating Scale Model (ARSM) was utilized for data analysis. The students indicated that the program has intermediate to high impact on research and instruction and low impact on tutorial and counseling services and outreach programs.
\end{abstract}

Keywords: Item Response Theory; HBCUs; Rasch Rating Scale Model; Title III program

\section{INTRODUCTION}

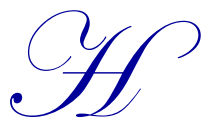

istorically Black Colleges and Universities (HBCUs) constitute only 3\% of all U.S. colleges and universities, yet they confer about $11 \%$ of doctoral degrees earned by African Americans. In addition, HBCUs continue to account for a disproportionately high number of diverse minority entrants into the labor force (NAFEO, 2009). They have also contributed significantly to low-income and minority students in obtaining post-secondary education particularly in the areas of science, engineering, and education (USDE, 1999; Field, 2009). Given the fact that minority-serving institutions cater for students who will be the majority in the future workforce, and as the number of minority students continues to grow, proponents elucidate that the practices, experiences, and perspective of HBCUs are essential to all of higher learning institutions (Kelderman, 2010).

A significant number of African Americans students who attend HBCUs disproportionately came from low-income families, had poor high school achievement scores, and had lower standardized test scores. Despite these factors, proponents contend that HBCUs are better equipped and are able to prepare these students academically, psychologically, and socially than predominantly white institutions (Lucas, 1994). Congress found that HBCUs had in fact contributed significantly to African Americans and low-income students in obtaining postsecondary degrees. Subsequently, the U.S. Congress approved financial assistance in the form of grant awards under Title III, Part B of the Higher Education Act of 1965 for graduate and professional programs at HBCUs that were making significant contributions to specific doctoral and professional levels (USDE, 1999). 
The 1986 amendments to the Higher Education Act of 1965 (P.L. 99-498), warranted major changes in funding procedures and the use of race-specific language in the designation of HBCUs in the Title III, Part B section of the Higher Education Act of 1965. HBCUs would receive exclusive funding under Part B on a formula based method. The formula method for allocation is based on half of the institution's enrolled Pell grant recipients; onefourth of the institution's total number of graduates; and the remaining fourth from the institution's number of graduates who are attending graduate or professional degree programs in which African Americans are underrepresented (Boren et al., 1987).

The program aims at strengthening and building capacity of eligible doctoral programs in science, mathematics, technology, and engineering offered by HBCU institutions. Other eligible professional programs include law, dental, medicine, pharmacy, and veterinary science. Even though the program has provided notable resources for capacity building, what is not known is the program's extent of success or lack of success as determined by student stakeholders. The lack of systematic program evaluation contributes to some questions and skepticism on the efficacy of the program.

Kendrick (1981), Norman (1985), and Patrick (1992) conducted studies that assessed the impact of Title III on academic quality, institutional viability and sustainability of the program at eligible HBCUs. Results from their respective studies found that Title III funding contributed in strengthening the aforementioned areas. Impact studies on federal programs including Title III Program at minority serving institutions were conducted by the U.S. Government Accountability Office (GAO) in 2007 and 2009. The 2007 study noted limited feedback mechanisms that encouraged open communication from recipient institutions (Scott, 2007). The follow-up study in 2009 recommended a management oversight by the Department of Education and creating mechanisms for collecting feedback from recipient institutions (GAO, 2009). Subsequently, the Department of Education had taken some steps to increase communication with recipient institutions. Such measures include exploring the option of using webinars when conducting conferences for recipient institutions and an e-mail address for grantees to express their concerns and inquiries anonymously (Scott, 2010). Although the Department of Education had taken some steps toward increased communication with stakeholders, these efforts are still limited and are in the early stages of development. The aforementioned studies used content analysis to estimate the impact by reviewing the reports produced by program administrators. No study has used quantitative method and stakeholders to quantify the impact of the program. The aim of this study was to fill the existing gap by using students to quantify the impact of the program at minority serving institutions.

\section{THE EMPIRICAL MODEL}

In this study, respondents were asked to evaluate different statements and indicate their degree of agreement with the statements using a Likert scale (Likert, 1932). The statements are shown in Appendix 1. Based on the responses, each question or statement may be analyzed separately or some responses may be summed to create a score or a summative scale for a group of questions (Bradley, Sampson and Royal, 2006). However, it is not advisable to make inferences based upon the analysis of single question responses or a sub-set of questions that are used to measure a scaled latent variable such as the impact of Title III program (Johnson and Albert, 1999). Each statement contributes to a specific immeasurable domain (i.e., research and instruction; technology development; facilities improvement; student financial assistance; and student services) that are important to this study.

As shown in $\mathrm{n}$ appendix 1 , the format of the survey instrument was in a five point ordered Likert scale. Responses from these statements can be either treated as ordinal or interval-level measurements. Responses to a single Likert item are normally treated as ordinal data, because, one cannot assume that respondents' responses are equidistant (Fox, 2005). That is, if the data are ordinal, we can say that one score is higher than another, however, we cannot say how much higher. When responses to several items are summed to measure a latent variable such as the impact of the program and all statement in a survey instrument use the same Likert scale, the responses are treated as interval data. The interval data tells the distance between two points and the differences between each response are equal in distance (Zheng and Rabe-Hesketh, 2009).

Interval estimates from the Likert scale responses can be obtained by applying the Polytomous Rasch Models (PRM). The polytomous Rasch model is a generalization of the dichotomous Rasch model (Rasch, 1960, 
1980). For Likert scale responses, the polytomous Rasch model is used to measure the latent variable in a continuum scale in this case the impact of Title III part B program. Also, the model permits testing of the hypothesis that the statements in the Likert scale reflect increasing levels of the latent variable as intended (Rabe Hesketh and Skrondal, 2008). The common polytomous Rasch model is the Rating Scale model (RRSM) that assumes identical threshold distances across items (Andrich, 1978).

The RRSM can be operationalized as follows. Let $\mathrm{X}$ be a data matrix made up by the responses of $v=1, \ldots, N$ students who responds to $k=1, \ldots, K$ polytomous questions on a the same Likert scale such that $h=1, \ldots, M$ are response categories per question. The students are in the low and questions in the column. The polytomous rating scale model (RSM) as suggested by Andrich (1978) is:

$$
P\left(X_{v k}=h \mid \theta_{v}\right)=\frac{\exp \left[h\left(\theta_{v}-\left(\beta_{k}+\gamma_{h}\right)\right)\right]}{\sum_{l=1}^{M} \exp \left[l\left(\theta_{v}-\left(\beta_{k}+\gamma_{l}\right)\right)\right]} .
$$

Equation 1 expresses the probability of student $v$ giving a rating $h$ on question $k$. The parameter $\theta_{v}$ represent the latent scale (impact score) of student $v$, the parameter $\beta_{k}$ represent the difficulty of the parameter $k$, and $\gamma_{h}$ are category parameters representing the difficulty of giving a rating category $m$ to question $\mathrm{k}$ and the difficulty is considered to be the same for all questions. Generally, the parameters $\theta_{v}$ equals the student $v$ 's interval value on the latent scale measurement (perceived impact of the program). As the value of $\theta_{v}$ increase, the probability of selecting response $h$ in a monotonic manner increases. The $\beta_{k}$ parameters measure the location effect for question $k$, which depend on both the response option and the particular question. It measures the impact at the activity level. The sum in the denominator ensures that for student $v$ the sum of probabilities over all response options to question $k$ equals 1.

In this study, students were nested in schools/faculties that are also nested in institutions/universities. This implies that student responses may vary by school and institutions. Multilevel modeling is therefore needed to capture variability in individual responses. Fox (2007) defines a general multilevel model with covariates such that respondents $(\mathrm{v}=1, \ldots, \mathrm{N})$ are nested within programs $(\mathrm{i}=1, \ldots, \mathrm{I})$ and the three surveyed universities $(\mathrm{j}=1,2,3)$. The model that quantifies the impact, which depends on student characteristics and that vary by program and university is specified as a three level structure as follows:

$$
P\left(X_{v k}=h \mid \theta_{v i j}\right)=\frac{\exp \left[\left(h\left(\theta_{v i j}-\left(\beta_{k}+\gamma_{h}\right)\right]\right.\right.}{\sum_{l=1}^{m} \exp \left[\left(l\left(\theta_{v i j}-\left(\beta_{k}+\gamma_{l}\right)\right]\right.\right.},
$$

Level 1 (individual): $\quad \theta_{v i j}=\sum_{q=0}^{Q} \alpha_{q i j} z_{q i j}+\varepsilon_{v i j}$

Level 2 (School): $\quad \alpha_{q i j}=\eta_{1 q j}+v_{i j}$,

Level 3 (Institutions): $\quad \eta_{1 q j}=\eta_{2 q 0}+v_{j}$.

In Equation 2, $\mathrm{z}$ is a matrix of level 1 covariates with a total numbers of $\mathrm{Q}$ variables that include a vector of one for an intercept when all variables are equal to zero. For strictly ordered and increasing model thresholds, the following constraints are usually imposed in Equation (2) for parameter identification purposes.

$$
\sum_{h=1}^{m} \gamma_{h}=0, \quad \text { and } \quad \gamma_{1}<\gamma_{2} \cdots \gamma_{h-1}
$$


When constraints in Equation (3) are imposed, all consecutive differences defining the item category response functions will be negative and the sum of the item category response function will add to one (Chajewski and Lewis, 2009).

\section{METHOD OF DATA COLLECTION AND ANALYSES}

Data for this study was collected from three HBCUs. The three institutions were selected using convenience sampling. Due to confidentiality reasons we cannot provide any information that can be used to identify the institutions. Eligible programs and institutions include: 1) Morehouse School of Medicine; 2) Meharry Medical School; 3) Charles R. Drew Postgraduate Medical School; 4) Clark-Atlanta University; 5) Tuskegee University School of Veterinary Medicine and other qualified graduate programs; 6) Xavier University School of Pharmacy and other qualified graduate programs; 7) Southern University School of Law and other qualified graduate programs; 8) Texas Southern University School of Law and School of Pharmacy and other qualified graduate programs; 9) Florida A\&M University School of Pharmaceutical Sciences and other qualified graduate programs; 10) North Carolina Central University School of Law and other qualified graduate programs; 11) Morgan State University qualified graduate program; 12) Hampton University qualified graduate program; 13) Alabama A\&M qualified graduate program; 14) North Carolina A\&T State University qualified graduate program; 15) University of Maryland Eastern Shore qualified graduate program; 16) Jackson State University qualified graduate program; 17) Norfolk State University qualified graduate programs; and 18) Tennessee State University qualified graduate programs.

Five criteria were used to select the eligible institutions: the amount of funding was in the upper quintile; the number of enrolment was over 5,000 students; the institution has at least two eligible doctoral and professional programs; more than $25 \%$ of the fund goes to student's scholarship and assistantship; and the institution was located in the south. These criteria were put in place in order to allow capturing a reasonable number of students per eligible programs institution and budget in case of follow-up. For each institution, level of funding depends on the size of eligible program. The U.S. Department of Education website indicate that the fiscal year 2011 appropriation for this program is $\$ 61,302,150$, a reduction of $\$ 122,850$ from the fiscal year 2010 level. During this study, the funding ranged between $\$ 2$ and $\$ 4$ million per year institution for $50 \%$ of the recipients. The sample institutions received on average of $\$ 9$ million per year.

We obtained e-mail addresses of administrators who manage eligible doctoral and professional programs from the three institution's website. An initial letter was electronically sent to these administrators soliciting support for this study. The letter briefly detailed the purpose and significance of the study. All contacted administrator agreed to participate. They directed the students who were currently receiving Title III funds in the form of scholarships and assistantships to fill in the survey instrument, which was deposited at surveymonkey.com. All potential respondents were given a three-week window to complete and electronically submit the survey. Measures were put in place to ensure that respondents were not able to submit more than one completed survey instrument. Two follow-up reminders were transmitted to administrators to remind students on the importance of the survey to enhance the response rate. After the three- week cutoff date, all of the submitted surveys were reviewed for completeness. A total of 56 completed surveys were received.

The respondents were primarily African American students. The purpose and goals of the Title III legislation in strengthening doctoral and professional programs in which African Americans are underrepresented and improving the graduate education opportunities for African Americans in STEM based fields (Electronic Code of Federal Regulations, 2011; USDE, 1999). Based on the number of students receiving scholarships and assistantships from Title III at each institution, the response rate was $67 \%$. A total of 56 complete surveys were received, that is, 13, 34, and 9 from the three institutions. Female constituted $70 \%$ of the respondents and $76 \%$ have received the funding for 2 to 4 years. Respondent's enrollment by academic programs was as follows: science and technology (38\%), science and mathematics education (12\%), health sciences (4\%), and law (2\%).

The survey instrument was divided into four sections. The demographic section asked questions regarding the name of the institution, the respondent's gender, how long the respondent has been enrolled in their respective program, and the academic program in which the respondent is currently enrolled. The impact assessment section 
has seventeen questions (Appendix 1). The questions were designed to assess the impact of the Title III program on five domains: research and instruction; technology development; facilities improvement; student financial assistance; and student services. All questions were in a five ordered Likert Scale coded from 1 to 5 with a greater score indicating a favorable impact. The response categories were coded as $1=$ strongly disagree, $2=$ disagree, $3=$ neither agree nor disagree, $4=$ agree, and $5=$ strongly agree. The third section has questions designed to obtain information on strategies regarding improvement and communication of the Title III program success. The last section allowed the respondent to give other views or comments. This paper presents the results of student's responses.

The questions/statements in Appendix 1 were developed by taking into account allowable expenditures and expected measurable outcomes. Validity and reliability of the survey instrument were tested using face and content analyses. Face and content validity was substantiated by a focus group knowledgeable of Part B, section 326 of the Title III Program. The focus group carefully reviewed the survey instrument and assisted in providing guidance in constructing the instrument statements. In addition, they were required to determine to whether the instrument statement looks valid in terms of measuring the impact of the program. They also rated each statement to determine how essential a particular statement is; in measuring impact of the program. Statements of the survey instrument where added, dropped and modified accordingly.

The Rasch scaling model as defined in Equation (2) was used for data analyses. This is because the responses to the question in Appendix 1 were categorical, ordinal and the same across all questions. The covariates included in the level one model were: a dummy variable for gender and how long a respondent was enrolled at current institution (i.e., $0=<=2$ years and $1=2>$ year). For level two and three, the respondents were grouped by academic program in which a respondent is enrolled and the university where the program belong, respectively. Due to relatively small sample size, programs were grouped into two groups: agriculture, education and graduate studies, law and other (group 1); and dental, medicine, other medical studies, nursing, sciences, and veterinary (group 2). Notice that Equation (2) investigates whether there are any statistical significance differences among programs and universities (i.e., does impact of the program differ by program or/and universities?). Equation (2) was estimated using gllamm in Stata. The program gllamm runs in statistical package Stata and estimates Generalized linear Latent and Mixed Models by maximum likelihood (Rabe-Hesketh, Skrondal and Pickles, 2004a, 2004b).

\section{RESULTS AND DISCUSSION}

Estimated question parameters (parameters $\beta_{k}$ and $\gamma_{\mathrm{h}}$ in Equation 2) are presented in Table 1.The hypothesis that all variables include in (Equation 2) was statistically insignificant was rejected at a more than $1 \%$ level of significance as shown by the likelihood ratio test. The step parameters represent $\left(\gamma_{\mathrm{h}}\right)$ in Equation (2) and the second expression in Equation 3. All four parameters were statistically significant. This implies that they are different from zero. We used the lower tail t-test to test the null hypotheses that subsequent parameters are equal (i.e., $\gamma_{1}=\gamma_{2} ; \gamma_{2}=\gamma_{3}$; and $\gamma_{3}=\gamma_{4}$. The three hypotheses were rejected at $1 \%$ level of significance. Because the parameters increases in value, it can be stated that "strongly agree" was infrequently scored when compared to "agree." Also, "agree" was infrequently scored when compare to neither "agree nor disagree" and so on.

In Table 1, when $\mathbf{P}>|\mathbf{z}|<\mathbf{0 . 0 5}$ the estimated parameters in not statistically significant from zero. This means that the statement has limited influence on the corresponding domain. For example,Q1 and Q2 have limited influence in constructing research and instruction domain. The magnitude value of item parameters $\left(\beta_{k}\right)$ are used to rank the statements regarding the level of impact on tittle III part B programs. The lowest item difficulty score was 0.81 , which represent lowest difficulty or highest impact. The score was for statement number 12 in Appendix 1(i.e., Q12: Title III funds have assisted with my tuition costs). The highest item difficulty score was 2 that represent the highest difficulty or lowest impact. This highest score was for statement number 7: Title III funds have increased the availability of online courses in my doctoral or professional program. Other low difficulty scores (high impact) included statement 14 (title III funds have assisted me in obtaining a graduate, research, or teaching assistantship), statement 13 (title III funds have assisted with the cost of school supplies) and statements one and two (title III funds have aided in the area of research in doctoral and/or professional programs and title III funds have aided in the area of instruction in doctoral and/or professional programs, respectively). All low difficulty scores indicating areas of program's high impact were in two domains: and scholarships, fellowship and other financial assistance and 
research and instruction. High difficulty scores indicating areas of program's least impact were in the facility construction, maintenance and renovation and student services. Therefore, results in Table 1 indicate that majority of students were satisfied with impact of the Title III programs in terms of scholarships, fellowship and other financial assistance. The least impact was on facility construction, maintenance and renovation.

Table 1: Estimates of Item Parameters by the Rasch Rating Scale Model

\begin{tabular}{|c|c|c|c|c|c|c|c|}
\hline \multirow[t]{2}{*}{ Domain and Questions } & & \multirow{2}{*}{$\begin{array}{l}\text { Coef. } \\
\left(\beta_{k} / \gamma_{h}\right)\end{array}$} & \multirow{2}{*}{$\begin{array}{l}\text { Std. } \\
\text { Err. }\end{array}$} & \multirow[t]{2}{*}{$\mathbf{z}$} & \multirow[t]{2}{*}{$\mathbf{P}>|\mathbf{z}|$} & \multicolumn{2}{|l|}{$95 \% \mathrm{CI}$} \\
\hline & & & & & & Lower & Upper \\
\hline \multirow{3}{*}{ Research and Instruction } & Q1 & 0.34 & 0.34 & 1.00 & 0.32 & -0.32 & 1.00 \\
\hline & $\mathrm{Q} 2$ & 0.39 & 0.34 & 1.16 & 0.25 & -0.27 & 1.05 \\
\hline & Q3 & 1.21 & 0.34 & 3.53 & 0.00 & 0.54 & 1.88 \\
\hline \multirow[t]{5}{*}{ Technology } & Q4 & 1.21 & 0.34 & 3.53 & 0.00 & 0.54 & 1.88 \\
\hline & Q5 & 0.88 & 0.34 & 2.60 & 0.01 & 0.22 & 1.55 \\
\hline & Q6 & 1.28 & 0.34 & 3.72 & 0.00 & 0.60 & 1.95 \\
\hline & Q7 & 2.00 & 0.35 & 5.66 & 0.00 & 1.31 & 2.69 \\
\hline & Q8 & 0.88 & 0.34 & 2.60 & 0.01 & 0.22 & 1.55 \\
\hline Facility Construction, Maintenance, and & Q9 & 1.75 & 0.35 & 5.01 & 0.00 & 1.07 & 2.43 \\
\hline \multirow[t]{2}{*}{ Renovation } & Q10 & 1.68 & 0.35 & 4.83 & 0.00 & 1.00 & 2.36 \\
\hline & Q11 & 1.75 & 0.35 & 5.01 & 0.00 & 1.07 & 2.43 \\
\hline Scholarships, Fellowships, and Other & Q12 & -0.81 & 0.35 & -2.29 & 0.02 & -1.50 & -0.12 \\
\hline \multirow[t]{2}{*}{ Financial Assistance } & Q13 & 0.20 & 0.34 & 0.61 & 0.55 & -0.46 & 0.87 \\
\hline & Q14 & -0.20 & 0.34 & -0.59 & 0.55 & -0.87 & 0.47 \\
\hline \multirow[t]{3}{*}{ Student Services } & Q15 & 1.25 & 0.34 & 3.66 & 0.00 & 0.58 & 1.93 \\
\hline & Q16 & 1.12 & 0.34 & 3.27 & 0.00 & 0.45 & 1.79 \\
\hline & Q17 & 1.21 & 0.34 & 3.53 & 0.00 & 0.54 & 1.88 \\
\hline Step 2 & $\gamma_{2}$ & -2.56 & 0.24 & -10.8 & 0.00 & -3.03 & -2.09 \\
\hline Step 3 & $\gamma_{3}$ & -2.51 & 0.19 & -13.5 & 0.00 & -2.87 & -2.14 \\
\hline Step 4 & $\gamma_{4}$ & -0.56 & 0.17 & -3.20 & 0.00 & -0.90 & -0.21 \\
\hline Sex & & 0.90 & 0.23 & 3.97 & & & \\
\hline Years in school & & 3.22 & 0.22 & 14.95 & & & \\
\hline Student faculty & & 0.12 & 0.25 & 2.03 & & & \\
\hline Level 2 variance & & 0.40 & 0.48 & 0.84 & & & \\
\hline Level 3 variance & & 0.25 & 0.92 & 3.72 & & & \\
\hline Likelihood ration test & & -1189.207 & $* * *$ & & & & \\
\hline
\end{tabular}

For research and instruction; the highest impact was on increased research supplies and equipment and increased instructional supplies and equipment. The least impact was on strengthening library holdings. Also, the students indicated that title III funds have expanded technology by increasing the access of wireless and other technologies. In terms of technology improvement, the least impact was on expanded telecommunications and availability of online courses. It can also be seen that majority of students indicated that the program has intermediate impact on student services (score ranged from 1.21 to 1.25) that include establishing or strengthening student services such as tutorial and counseling services, establishing or strengthening community outreach opportunities and enhancing teacher education opportunities designed to qualify students to teach in public school.

The distribution of the program impact scores $\left(\beta_{n}\right)$ is shown in Figure 1. The impact score is centered on zero and ranged from -1.36 and 1.28. The score of 34 students out of 56 students $(61 \%)$ was negative. In general, a student with low impact score (negative) has a high propensity of scoring "strongly disagree" on all statements. For high impact score (positive) the student has a high inclination of scoring "strongly agree" for most of the statements. Therefore, lowest impact score implies that a student indicated that the overall impact of the program was negligible and vice versa. Because the impact scores are centered at zero, it can be generalized that the first class in Figure 1 (<-1.36 score) represent no impact as indicated by one students $(1.79 \%)$. The second class $(-1.36--0.86$ score) represents low impact as indicated by $4(7.14 \%)$ students. The two middle classes $(-0.86-0.14$ score $)$ represent intermediate impact as indicated by 29 (51.79\%) students. High impact (0.63-1.14 score) and highest impact (>1.14 score) were indicated by $5(8.93 \%)$, and $3(5.36 \%)$ students, respectively. At least $67 \%$ of the students indicated that the program has intermediate to high impact. 


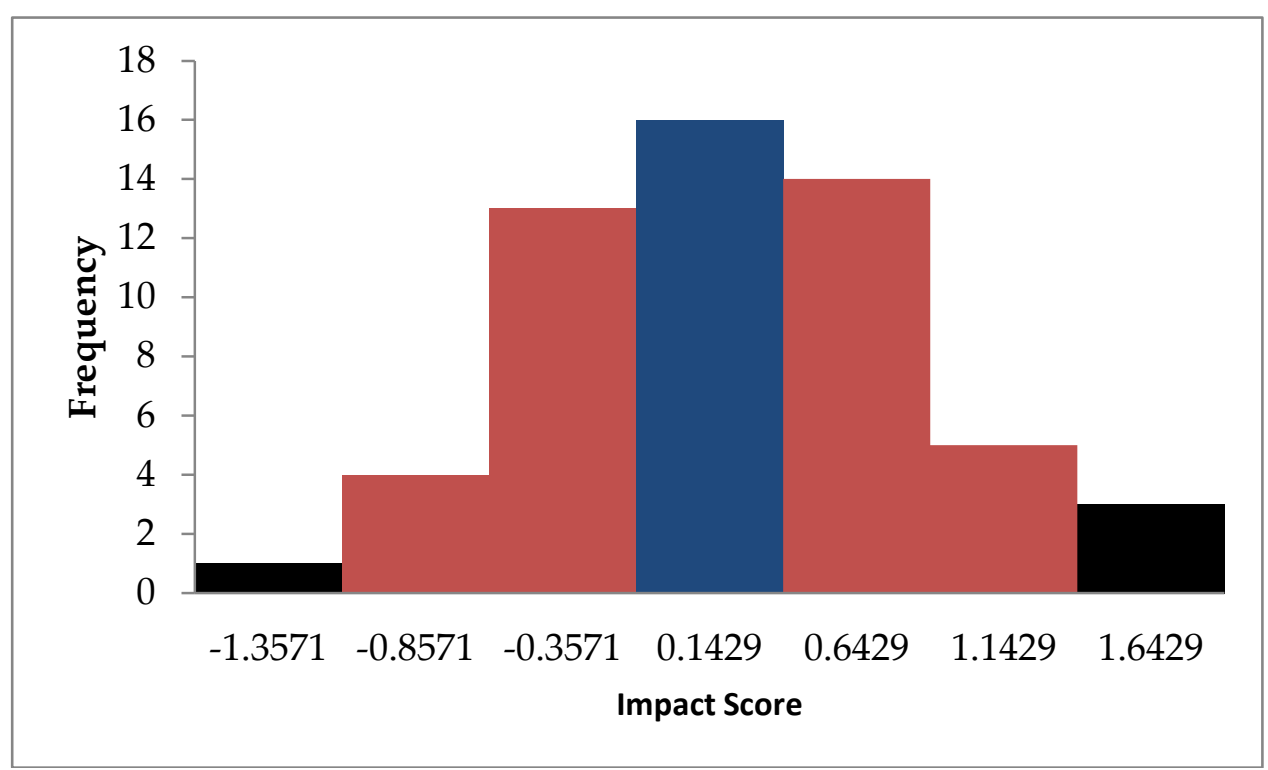

Figure 1: Frequency Distribution of the Estimated Impact Score

In order to compare difficulty parameters $\left(\beta_{k}\right)$ and student's impact scores $\left(\theta_{k}\right)$ across domains we use an item characteristics curves as shown in Figure 2. Item Characteristic Curve (ICC) also known as trace-lines, category response curves, or probability curves. The theoretical range of the impact would range from negative infinity (no impact) to positive infinity (high impact). For practical considerations we limit the range of values from -4 to +4 , with a midpoint of zero. The assumption behind the ICC is that each student has an underlying latent score on the impact of the program. At each level of impact, there is a certain probability that a student will give a certain score to a given question. The probability is low for students who think that the program has low impact and the probability is high for respondent who think that the program has high impact. This means that the student with high score will have a higher probability of endorsing response categories that are consistent with high impact (i.e., strongly agree). In Figure 2, the probability of giving a high score to any of the question in the survey instrument is near zero, for a student with the lowest levels of score on the impact of Title III program. The probability increases and at the highest levels of impact score, the probability of giving "Strongly Agree" approaches one. The curves in Figure 2 therefore show the relationship between the probability of scoring "strongly agree" to questions and the impact rating by the students.

In addition, Figure 2 shows two technical properties of an item characteristic curve. The first is the difficulty of the question, which describes, in this case, the position of the question along the impact scale on the horizontal axis. Low difficulty score will appear among students with high- impact score (easy item) and high score on item will appear among students with low- impact (difficulty item). The second technical property is discrimination, which describes how well a question can differentiate between students indicating that the program has low impact and those indicating that the programs has impact. This property essentially reflects the steepness of the item characteristic curve in its middle section. The steeper the curve, the better the question can discriminate and the flatter the curve, the less the question is able to discriminate. This is because the probability of "strongly agree" response at low impact levels is nearly the same as it is at high impact levels.

Based on the results in Figure 2, all questions have the same level of discrimination (the curves do not cross) but differ with respect to discrimination power. In each domain, the left hand curves represent an easy item (because the probability of "strongly agree" is high for low- impact students and approaches one for high- impact students). This means that majority of student scored the questions as "strongly agree". The center curves represent items of medium difficulty because the probability of "strongly agree" is low at the lowest impact levels (around 0.5 in the middle of the impact scale) and near one at the highest impact levels. These items were scored as "agree" on average. The right-hand curve represents a hard item-few students scored the question as "strongly agree". The 
probability of "strongly agree" is low along the impact scale and increases only when the higher impact levels are reached.
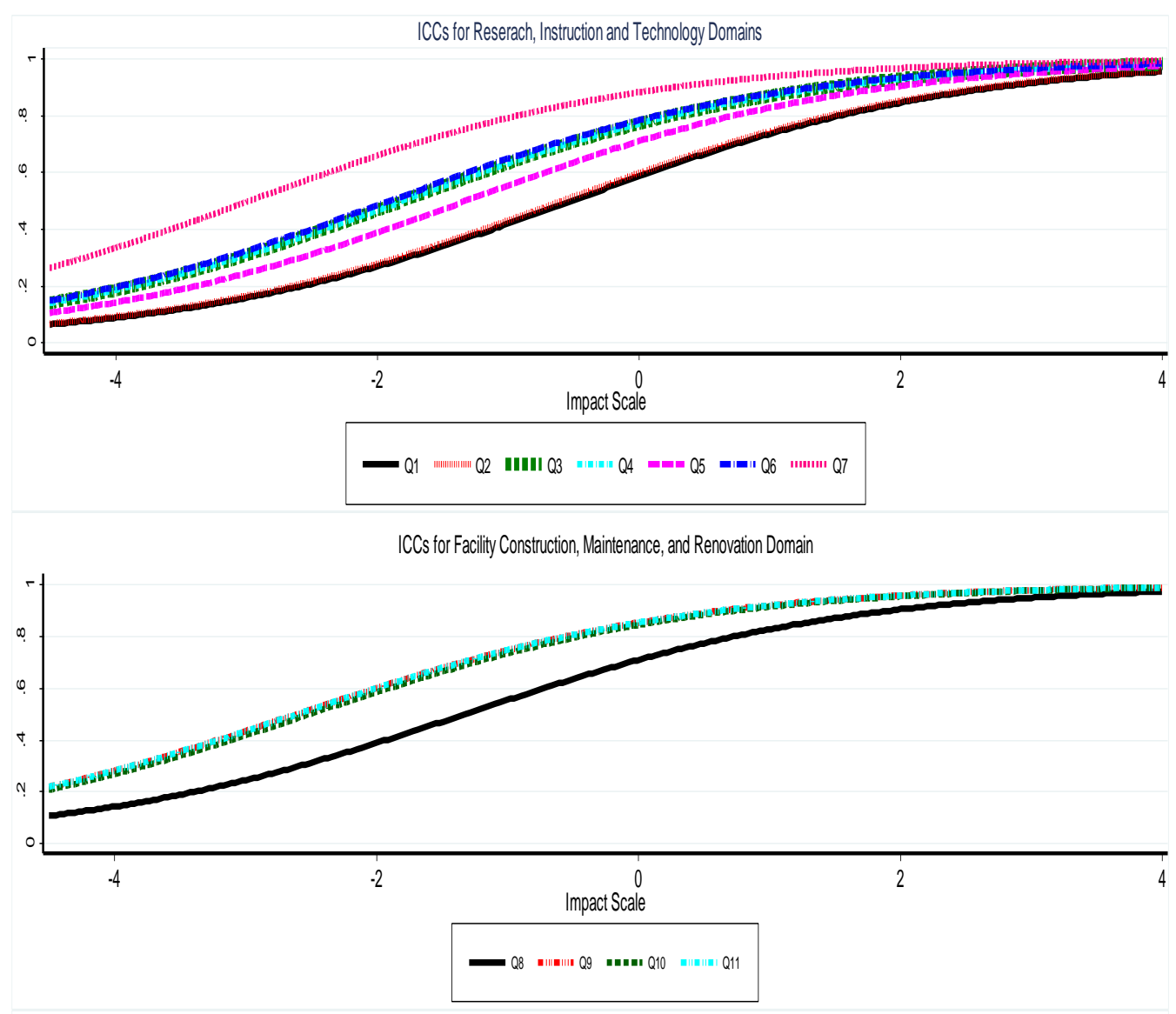

ICCs for Scholarships, Fellowships, Other Financial Assistancen and Student Service Domains

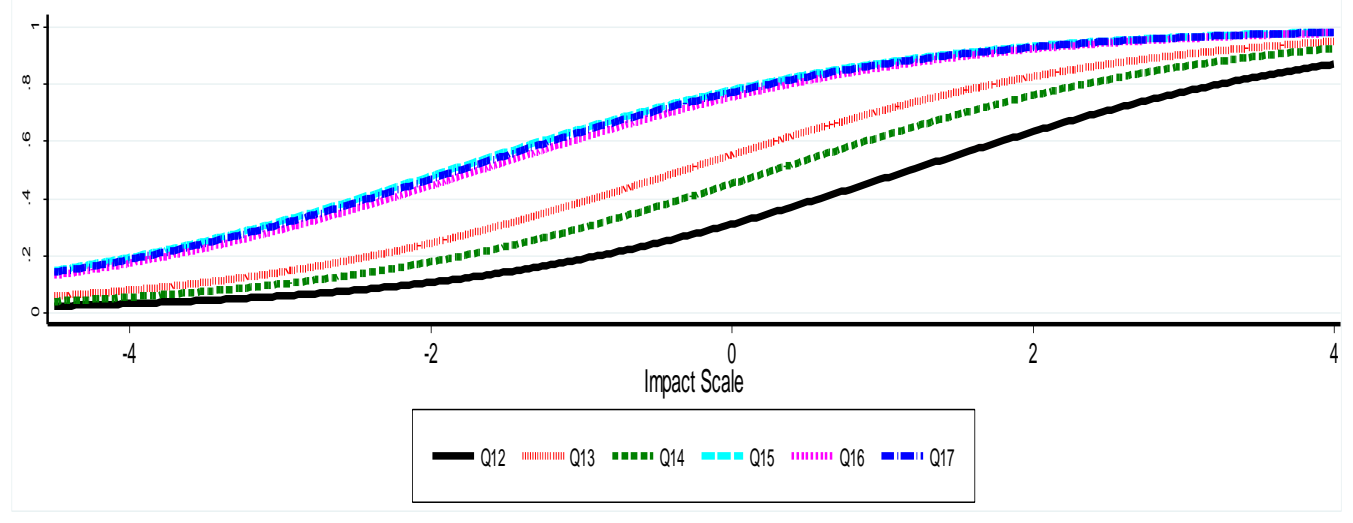

Figure 2 Item Characteristics Curves for all Five Domains 


\section{SUMMARY AND CONCLUSION}

The federal funds under Part B, section 326 of the Title III program are granted to institutions that are making a substantial contribution to the legal, medical, dental, veterinary, or other graduate education opportunities in mathematics, engineering, or the physical or natural sciences for minority students. The grant may be used for seven domains: to purchase, rental or lease of scientific or laboratory equipment for educational purposes, including instructional and research purposes; construction, maintenance, renovation, and improvement in classroom, library, laboratory, and other instructional facilities, including purchase or rental of telecommunications technology equipment or services; and purchase of library books, periodicals, technical and other scientific journals, microfilm, microfiche, and other educational materials, including telecommunications program materials. Other use include: providing scholarships, fellowships, and other financial assistance for needy graduate and professional students enrolled in eligible doctoral programs; establishing or improving a development office to strengthen and increase contributions from alumni and the private sector; assisting in the establishment or maintenance of an institutional endowment to facilitate financial independence; and funding management activities and acquisition of equipment, including software, for use in strengthening funds management and management information systems (USDE,1999). Since the program inception in 1965 , no study has been conducted to quantify the impact of the programs as viewed by students. This study aimed at filling this gap. Data was collected using an electronically administered survey instruments to students. The survey instrument has seventeen questions/statements divide into five domains. The domains constitute the allowed expenditures under title III part B program. The domains included research and instruction, technology development, facilities improvement, student financial assistance, and student services. The statements were on a fiver ordered Likert scale and were designed to assess to the impact of the programs on activities funded by programs. The codes were (1=strongly disagree; $2=$ disagree; $3=$ neither agree nor disagree; $4=$ agree; and $5=$ strongly agree). The survey was completed by fifty six students from three eligible institutions with representation from different schools and colleges. We used a multilevel Rasch Rating scale models to analyze the data. This allowed identifying both the level of impact at the activity and programs level.

At the activity level, for research and instruction and technology domains, the student indicated that Title III program have impact on area of research and expanding telecommunications within eligible doctoral or professional program. The least impact was on increasing the availability of online courses and aiding in the area of student research. Relatively, on facility construction, maintenance and renovation, the least impact was on building improvement. For the fellowship and student assistance domains Title III program has highest impact with on tuition and cost of school supplies. The least impact was on establishing or strengthening student services in terms of developing tutorial services and counseling services and also enhancing teacher education opportunities designed to qualify students to teach in public schools. The highest impact was on student financial assistance and student services and the least impact were on facilities improvement and student services. Overall, 67\% of the students indicated that the program has intermediate to high impact. Apart from scholarship and fellowship, the administrators need to focus on other areas of mandated by the program such as physical facilities improvement and strengthening student services. The administrators can also use students to communicate the impact of the program. The survey instruments used in this study needs to be improved by including more questions to capture different activity levels of title III part B program. Addition studies covering all eligible institutions are also important in quantifying the impact of the programs by studying current students and alumni of the program.

\section{AUTHOR INFORMATION}

Dr. Aloyce R. Kaliba is the Associate Professor of Economics, Department of Economics and Finance, College of Business, Southern University and A\&M College, P.O. Box 9723, Baton Rouge, LA 70813; aloycekkaliba@subr.edu; Tel: 225771 5962; Fax: 225771 5262. His current research interests include using item theory models in project evaluation and impact assessment. (Corresponding author)

Dr. Kimberly K. Powell holds a Ph.D. in Urban Higher Education from Jackson State University in Jackson, Mississippi. Dr. Powell is the Grant Coordinator for the Office of Graduate Studies at Southern University and A\&M College in Baton Rouge, Louisiana. Her research interests include diversity management and marketing in higher education, higher education policy, and resource capacity building. Dr. Powell is also an Adjunct Professor in 
the Department of Marketing and Management, College of Business at Southern University and A\&M College, P.O. Box 9860, Baton Rouge, LA 70813-9860; kimberly_powell@ subr.edu.

Dr. Walter L. Crockett is the Associate Director and Professor with the Executive PhD Program in Urban Higher Education at Jackson State University, 1400 J.R. Lynch Street, JSU Box 17209 , Jackson, MS 39217-0209; walter.crokett@jsums.edu. His research interests are in the area of student motivation and academic performance.

\section{REFERENCES}

1. Andrich, D. (1978). A rating formulation for ordered response categories. Psychometrika, 43, 561-73.

2. Bradley, K. Sampson, S. and K. Royal. (2006). Applying the rasch rating scale model to gain insight into student's conceptualization of quality mathematics instruction. Mathematics Education Research Journal 18(2), 11-26.

3. Boren, S., Irwin, P., Lyke, B., Riddle, W., Stedman, J., Fraas, C., Jordan, K., Gregory, W. (1987). The higher education amendments of 1986 (P.L. 99-498): A summary of revisions. 87-187 EPW. (ED294485) Retrieved from http://www.eric.ed.gov

4. Chajewski, M., Lewis, C. (2009). Optimizing item exposure control algorithms for polytomous computerized adaptive tests with restricted item pools. In D. J. Weiss (Ed.). Proceedings of the 2009 GMAC Conference on Computerized Adaptive Testing.

5. Creswell, J. W. (2009). Research design: Qualitative, quantitative, and mixed methods approaches. Thousand Oaks, CA: Sage Publications

6. $\quad$ Eighty-Ninth Congress H.R. 9567 (1965). The Higher Education Act of 1965 (P.L. 89-329). Retrieved January 10, 2010 from http://ftp.resource.org/gao.gov/89-329/00004C57.pdf

7. ExpectMore.gov. (2005). Program assessment - Strengthening historically Black graduate institutions. Retrieved on February 20, 2010, from http://www.whitehouse.gov/omb/expectmore/summary/10003317.2005.html

8. Electronic Code of Federal Regulations (2011). Title 34: Education, Part 609 - strengthening historically black graduate education institutions program. Retrieved August 2, 2011 from http://ecfr.gpoaccess.gov/cgi/t/text/textdx?c=ecfr\&sid=e40f61a977153abcceb7a9b4be943cb4\&rgn=div5\&v iew $=$ text\&node $=34: 3 \cdot 1 \cdot 3 \cdot 1.9$ \&idno $=34$

9. Field, K. (2009). Historically black colleges seek continued supplemental aid. The Chronicle of Higher Education, 55. Retrieved on May 26, 2010, from http://chronicle.com/article/Historically-BlackColleges/47288/

10. Fox, J.P. (2005). Multilevel IRT using dichotomous and polytomous response data. British Journal of Mathematical and Statistical Psychology, 58, 145-172.

11. Fong, D.Y, Ho, S.Y., and T. H. Lam (2010). Evaluation of internal reliability in the presence of inconsistent responses. Health and Quality of Life Outcomes, 8, 27.

12. Johnson, V. E. and J.H. Albert (1999). Ordinal Data Modeling. Statistics for social science and public policy. New York: Springer.

13. Kelderman, E. (2010). White house adviser urges historically black colleges to change how they are seen. The Chronicle of Higher Education, 56. Retrieved on May 26, 2010 from http://chronicle.com/article/White-House-Adviser-Urges/65218/

14. Kendrick, C.M.C. (1981). The impact of the advanced institutional development program on the curriculum of traditionally black colleges and universities. Dissertation Abstract International, 42-04, AA118120365.

15. Likert, L.A. (1932). Technique for the Measurement of Attitudes. Archives of Psychology 140: 1-55.

16. Lucas, C. (Ed.). 1994. American higher education: A history. New York, NY: St. Martin's Press.

17. National Association for Equal Opportunity in Higher Education (2009). HBCU and PBI policy recommendations for Obama economic stimulus package and first 100 days. Retrieved on December 22, 2009 from http://www.nafeo.org/community/index.php

18. Norman, M.K. (1985). The impact of the advanced institutional development program on the institutional viability of seven black 1890 land grant institutions (title III). Doctoral Dissertation. University of Missouri - Columbia. 
19. Patrick, E. M. (1992). A descriptive study of Title III fund use by historically Black colleges and universities since enactment of Part B of the 1986 Higher Education Act Amendments. (Doctoral dissertation) University of Connecticut. Storrs, Manfield, CT.

20. Rasch, G. (1960/1980). Probabilistic models for some intelligence and attainment tests. (Copenhagen, Danish Institute for Educational Research), expanded edition (1980) with foreword and afterword by B.D. Wright. Chicago: The University of Chicago.

21. Rabe-Hesketh, S., Skrondal, A. and Pickles, A. (2004a). Generalized multilevel structural equation modeling. Psychometrika 69, 167-190.

22. Rabe-Hesketh, S., Skrondal, A. and A. Pickles (2004b). GLLAMM Manual. U.C. Berkeley Division of Biostatistics Working Paper Series. Working Paper 160. Available at http://www.gllamm.org/docum.html

23. Rabe-Hesketh, S and A. Skrondal (2008). Multilevel and longitudinal modeling using stata. College Station, TX: Stata Press Publication.

24. Scott, G. A. (2007). Low-income and minority serving institutions: Education has taken steps to improve monitoring and assistance, but further progress is needed: Testimony before the Subcommittee on Higher Education, Lifelong Learning, and Competitiveness, Committee on Education and Labor, House of Representatives. Testimony, GAO-07-926T. [Washington, D.C.]: U.S. Govt. Accountability Office. Retrieved May 26, 2010 from http://www.gao.gov/new.items/d07926t.pdf

25. Scott, G.A. (2010). Low-income and minority serving institutions: Sustained attention needed to improve education's oversight of grant programs. Testimony, GAO-10-659T. [Washington, DC]: U.S. Govt. Accountability Office. Retrieved May 26, 2010 from http://www.gao.gov/new.items/d10659t.pdf

26. United States Department of Education. (1999). Higher education act of 1965: part b-strengthening historically black graduate institutions. Retrieved September 29, 2008 from http://www2.ed.gov/programs/idueshbgi/hbgi-laws326.pdf

27. United States Government Accountability Office. (2009). Low-Income and minority serving institutions: Management attention to long-standing concerns needed to improve education's oversight of grant programs. Report to the Chairman, Subcommittee on Higher Education, Lifelong Learning, and Competitiveness, Committee on Education and Labor, House of Representatives. GAO-09-309. Retrieved December 7, 2009 from http://www.gao.gov/new.items/d09309.pdf

28. Zheng, X and S. Rabe-Hesketh (2009). Estimating parameters of dichotomous and ordinal item response models with gllamm. Stata Journal, 7,3, 313-333. 


\section{Appendix 1: Questions in the Survey Instrument}

Code: $1=$ strongly disagree, $2=$ disagree, $3=$ =neither agree nor disagree, $4=$ agree, and $5=$ =strongly agree

\section{Research and Instruction}

Q1. Title III funds have aided in the area of research in doctoral and/or professional programs (i.e. increased research supplies and equipment).

Q2. Title III funds have aided in the area of instruction in doctoral and/or professional programs (i.e. increased instructional supplies and equipment).

Q3. Title III funds have strengthened library holdings (i.e. microfilm, academic journals, etc.).

\section{Technology}

Q4. Title III funds have assisted in strengthening library technology.

Q5. Title III funds have expanded technology in my doctoral or professional program (i.e. increased wireless access, etc.).

Q6. Title III funds have expanded telecommunications within my doctoral or professional program (i.e. teleconferencing, videoconferencing).

Q7. Title III funds have increased the availability of online courses in my doctoral or professional program.

\section{Facility Construction, Maintenance, and Renovation}

Q8. Title III funds have assisted in improving buildings in my doctoral or professional program.

Q9. Title III funds have assisted in improving laboratory facilities in my doctoral or professional program.

Q10. Title III funds have assisted in improving offices in my doctoral or professional program.

Q11. Title III funds have assisted in improving classrooms in my doctoral or professional program.

\section{Scholarships, Fellowships, and Other Financial Assistance}

Q12. Title III funds have assisted with my tuition costs.

Q13. Title III funds have assisted with the cost of school supplies.

Q14. Title III funds have assisted me in obtaining a graduate, research, or teaching assistantship.

\section{Student Services}

Q15. Title III funds have assisted in establishing or strengthening student services (i.e. tutorial services, counseling services, etc.) in my doctoral or professional program.

Q16. Title III funds have assisted in establishing or strengthening community outreach opportunities in my doctoral or professional program that will encourage elementary and secondary school students to develop the academic skills and the interest to pursue postsecondary education.

Q17. Title III funds have enhanced teacher education opportunities in my doctoral or professional program designed to qualify students to teach in public schools. 